\title{
TWO-LEVEL ENVIRONMENT FOR SUPPLY CHAIN MANAGEMENT
}

\author{
Carlos Machado $^{2}$, Marcius F. Carvalho ${ }^{1,2}$ an 1 Pythágoras G. Furtado ${ }^{2}$ \\ ${ }^{1}$ National Institute of Information Technology (ITI), Campinas - SP - BRAZIL \\ ${ }^{2}$ Mechanical Engineering School - UNICAMP, Campinas - SP - BRAZIL \\ marcius.carvalho@cenpra.gov.br; cmachado_br@yahoo.com; furtado@fem.unicamp.br
}

\begin{abstract}
In today's highly competitive market products have to flow through several organisations to reach the final customer. This flow must be managed considering organization's objectives and supply chain objectives. This paper presents an ongoing development environment for supporting an enterprise to negotiate its interest in the context of integrated supply chain decision process. It is composed of two levels. At the first level the integrated timely production taking into account manly the cost and enterprises capacity is determined. At the second level the demand and production uncertainties and the business rules among enterprises are considered.
\end{abstract}

\section{INTRODUCTION}

Modern manufacturing enterprises are connected into a collaborative chain with a number of suppliers and customers having the objective of producing competitive products. The collaborative chain evolves with the time, due to new production and information technologies or new management approaches. A continuous review of their strategies, structures, partnership and manufacturing processes is required for competing in the ever changing, ever expanding global economy where the enterprises have to make decisions in full collaboration with business partners considering their internal objectives and the chain objectives in strategic, tactical and operational levels. Each long-term decision is an assignment or target to the next shorter-term decision that has to be co-ordinated within time horizon and enterprise space resulting in a large-scale problem.

The literature considers two approaches to solve this problem: a generative technique takes a set of criteria and constraints and generates (prescribes) values for a set of decision variables (Carvalho and Furtado, 2002) and an evaluative technique that evaluates the performance of a system under uncertainty (Carvalho and Machado, 2000). A combination of both approaches known as simulationoptimization is growing of importance (Law, 2002; Azadivar, 1999). Simulationoptimization is the process of finding the best values of some decision variables for a system where the performance is evaluated based on the output of a simulation model (Azadivar, 1999). In this approach, different search methods have been 
coupled with optimization packages to find the best solution. Azadivar comments that for complex systems, the team simulation experts will focus their efforts on a validation of a simulation model that probably will not be easily interfaced with optimization packages and he recommends developments of intelligent frameworks to improve the interface of optimization-simulation models.

This paper proposes a two-level ongoing development of an environment specially designed to support production and operation decisions within the supply chain concepts. At the first level, a generative technique takes a set of criteria and constraints and generates (prescribes) a set of decisions. At the second level, an evaluative technique evaluates, according to a predefined rules, the decisions set taken at the first level, considering the performance of a system under uncertainty.

The generative technique is a mathematical approach of fitting together the timely production requirements of partner enterprises, grouped in a chain, with forecasted demand. It solves a multi-period capacitated production planning production problem together with material requirement considering satisfaction in terms of profit (cost). Due to the impractical amount of computer time and some modeling difficulties it is limited to the deterministic linear programming where business rules and random effects, including machine failures and demand uncertainties, cannot be analyzed.

As output it generates the quantity and the time of order releases for each enterprise of the chain considering the associated enterprise capacity, raw material availability, demand forecast and costs, in summary it co-ordinates the flow of material diminishing the major supply-chain planning problem: the impact of demand fluctuation on the production system known as bullwhip effect (Lee $e$ t al, 1997). This mathematical approach works as push system since it establish the latest optimum date when the production must start to meet the demand forecasted due date. But is weak in considering the information flow among enterprises and its sensitivity with respect to disturbances and its simplistic view of capacity are some deficiencies.

The way to refine these decisions is through an evaluative technique. It uses a more accurate representation of the production system and form a set of predefined decisions (level of demand attainment, machine availability, etc.), some of then determined by the generative technique, and business rules it measures the system performance under those decisions (Gershwin and Hildebrant, 1986). Evaluative techniques describe the supply chain by equations and rules and simulate its behavior with the objective of: understand the way it evolves, predict its future behavior and identify strategies to minimize system inefficiencies.

The evaluative technique can simulate enterprise's production and stock rules, the dynamic of customers demand, the speed of information and material flow among enterprises and help to analyze the overall impact of these elements in the supply-chain service level. Then it considers one more dimension than the generative technique, the information flow. It works as a pull system and cannot organize the temporal production since it does not consider future demand and capacity. It also neglects the production and transportation costs.

The proposed environment permits the diagnosis of problems and possible solutions evaluation for planning and operation scenarios prior to the implementation and can constitute a base for negotiation of trade-offs (i.e stock level and service level) among enterprises. 
The paper is organized as: the next section presents a two-level hierarchical approach to support the supply chain decision process and defines the inputs and outputs of each level. In the following a case study that shows the application of a two level approach to coordinate seven enterprises and four production periods of the supply chain.

\section{HIERARCHICAL APPROACH}

Each hierarchical level of the suggested environment has its own characteristics, including length of the planning horizon, level of detail of the required information, forecasted demand and resources availability. The first level, here called logistic model, represents as network flow model, the supply chain production-planning problem. The second level, here called operational level, a simulation model represents the production and information systems. Inputs and outputs of each level are shown in the Figure 1.

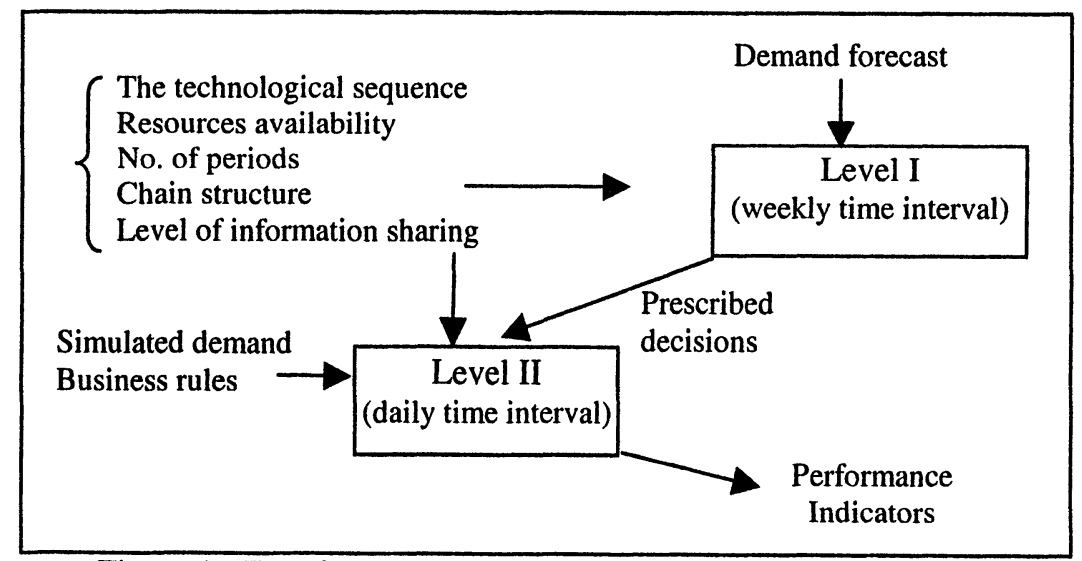

Figure 1 - Two-level supply chain decision support environment

\subsection{Logistic Model}

The logistic model is concerned with production allocation among enterprise resources over a time period to meet some pre-determined goals, e.g. demand attainment, production level, cost optimization, etc. It considers the physical flows of parts/products from supplier's factories to customers or retails as a flow of items (raw material, semi-manufactured products, etc.) over the chain of enterprises. In its trajectory, an item waits to be processed, assembled or transported, and flows in its way until reach the end customer as in the Figure 2.a). The forecasted demand, enterprise production capacity and the technological sequence of operation and transportation are supposed to be known for each time interval of the planning horizon. The logistics models deal primarily with material flows across multienterprises having as fundamental modeling approach push information flow and decisions supported by generative technique. Job priorities, due-date requirements, release dates, cost, trade-offs between inventory level and delay in due dates are used as decision factors. The flow characteristic permits to model its production process as a well-structured network flow problem (Carvalho et al, 1999). The 
Figure 2.a) shows a supply chain composed of three production sub chains and two assembly plants. In the Figure 2.b) is presented the time-expanded graph for the network flow model where the horizontal arcs represent the enterprises with associated cost and capacity while the dashed vertical arcs represent the inventory to be held between two consecutive time periods. Some advantages of the network flow approach are: fast solution, allowing the managers to quickly respond to the dynamics of the market industry; fast update of the last scheduling; and ease problem formulation through graphical modeling. The pictorial modeling, i.e., the graphical definition of the routes can be extremely valuable in communicating and refining the model without the use of technical terminology. This decision level considers financial metrics and network flow optimization for the performance evaluation of the supply chain production system.

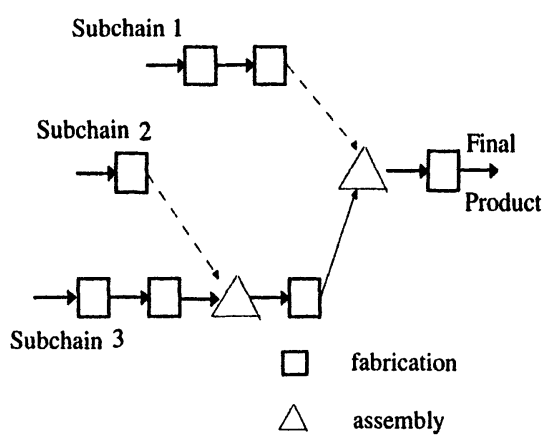

a)Supply Chain (SC)

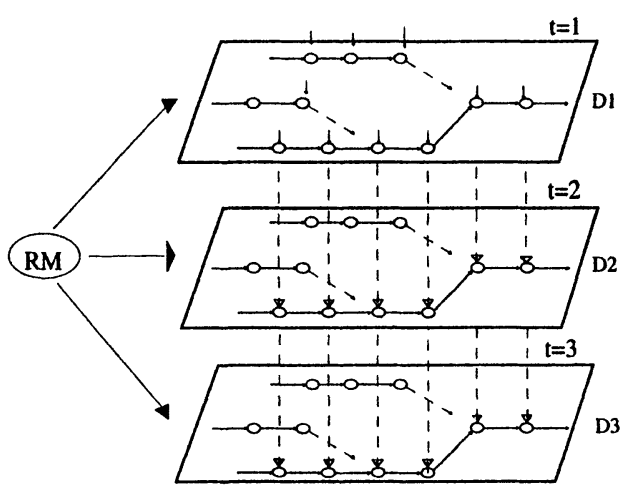

b)Graph representation of SC

Figure 2 - Production Supply Chain

A simplified modeling approach, that ignores the actual system behavior, is adopted by optimization approach in order to have a model solved in a short period of time. This level takes into account independent demand (forecasted demand), cost and production capacities of each production stage (enterprise or transportation) but lot size, uncertainties and business rules are not considered.

\subsection{Operational Level}

The dynamics of business process among enterprises and uncertainties related to demand and production resources (raw material and machines) are considered at this level. The chain, represented as a set of buyer-seller processes (clients, retailers, warehouses, assemblers and suppliers), is modeled as a WIP-driven discrete time simulation model. In the beginning of every time-period, an enterprise receives a request for new production order from downstream enterprise and "raw material" from upstream enterprises, executes its planning process and at the end of the period checks the WIP level. If the level is lower than a predefined value the enterprise will request material. The lower level of the WIP in each station can be settled dynamically according to a predefined service level. Since the demand oscillates, the 
inventory lower level must oscillate according to demand to maintain the same service level.

The supply chain simulation model has to represent the above business processes requirements. Then the environment allows the user to define management policies rules for driving the business process among enterprises. The management policies are extended JIT (Lee and Paek, 1995), distributed information and centralized information. The inventory rules follow a periodic replenishment policy defined by the user. The main inventory policies are (Simchi-Levi, 2000): s-S when the inventory level lows under s, an order is placed to make the inventory level reach $S$. $\mathrm{s}-\mathrm{Q}$ when the inventory level lows under s, a Q-size order is placed. Order to S every period, an order is placed to make the inventory level reach $S$. Order to $Q$ every period, a Q-size order is placed. Updated s. every period, the enterprise places an order to make the inventory level to reach $s$, where $s$ is based on the latest $n$ demands ( $\mathrm{n}$ defined by the user).

Demand and production capacity uncertainties must be considered. As it will be shown in a case study, the demand for each enterprise and each time interval is defined as a probabilistic function with mean equal to the target specified by the logistic model. At each time interval, the simulation updates the service level calculated as the number of fulfilled orders divided by the total number of orders.

\section{A CASE STUDY}

A case study shows the application of a two-level approach to coordinate seven enterprises distributed as in the Figure 3 and four production periods. The first stage, the retailer stage, has three sales points. They are connected to a distribution center

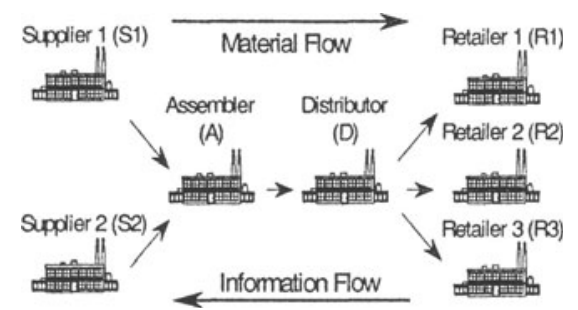

Figure 3 - Supply chain for the case study

that receives the products from an assembly plant. This plant has two suppliers.

\subsection{Logistic Level}

The Figure 4 shows the results of the supply chain production optimization considering 4 periods (the complete example is in Carvalho and Furtado, 2002) of the assembly plant of Figure 3. The horizontal arcs represent the flow of material (products in process and finished products) in the same period of time. Each arcs has a 3-uple that represent costs, minimum and maximum flow respectively. In the first time period, the 3 arcs of the graph represent a flow of 65 units of supplier material, 65 units of production with capacity for 95 units at most and 55 units of finished 
products delivered. The vertical arc has a flow of 10 units that represents an inventory of finished products between periods 1 and 2 .

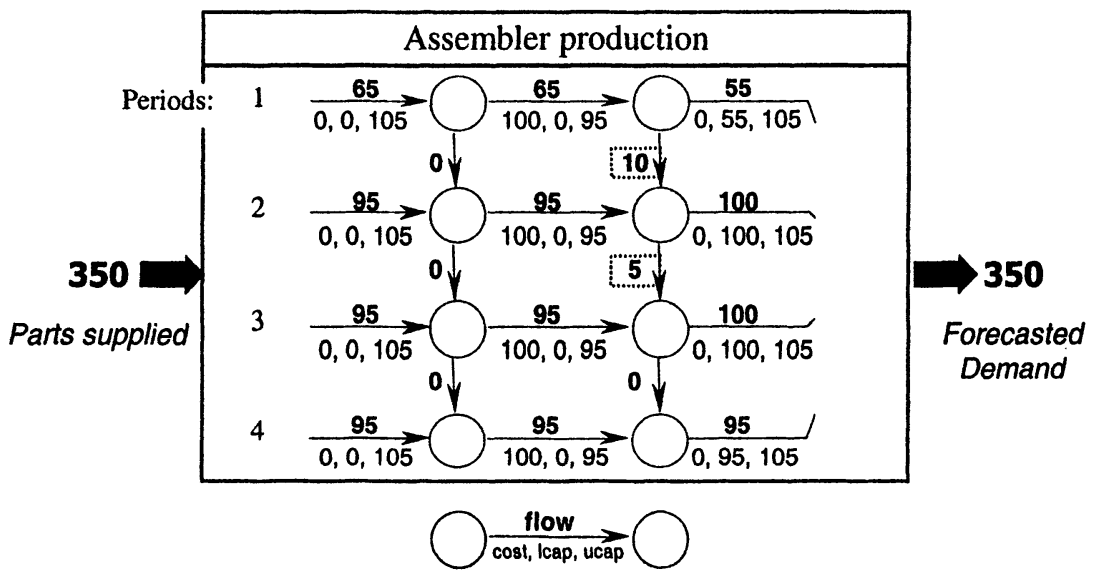

Figure 4 Logistic Planning for the assembly plant

The logistic model suggest to produce in the period 1 more than the required demand to compensate the capacity limitation of the period 2 and 3 , as shown in the vertical inventory arcs of the Figure 4. It means an option for extra inventory to avoid backorder.

\subsection{Operational Level}

The Figure 4 shows the logistic planning for the assembler plant extracted from the entire system. The simulation model of the assembly plant considers the production capacity equals to 95 units and the initial production order equals to 55 . The inventory policy is updated $s$ where $s$ is equal to:

$$
s=L D_{A V G}+D_{S T D} \sqrt{L} z
$$

Where: $\mathrm{L}$ is the supplier replenishment leadtime (periods), $\mathrm{D}_{\mathrm{AVG}}$ is the average demand, $\mathrm{D}_{\text {STD }}$ is the demand standard deviation and $\mathrm{z}$ is related to the service level. The demand follows a normal distribution with mean equals to the demand forecasted and $5 \%$ of standard deviation. The average demand is based on the simulated demand as shown in the Table 1 . The Table 2 shows the simulation output for the assembly plant.

Table 1 - Value of $s$

\begin{tabular}{|c|l|c|c|c|}
\hline \multicolumn{5}{|c|}{$\mathrm{L}=1, \mathrm{z}=1.88$ (service level of 97\%) } \\
\hline $\begin{array}{l}\text { Beginning } \\
\text { of Period }\end{array}$ & $\begin{array}{l}\text { Simulated } \\
\text { Demand }\end{array}$ & Average & $\begin{array}{l}\text { Standard } \\
\text { Deviation }\end{array}$ & $\mathrm{s}$ \\
\hline 1 & (initial value) 55 & 55 & 0 & 55 \\
\hline 2 & $55+59$ & 57 & 2.8 & 62 \\
\hline 3 & $55+59+106$ & 73.3 & 28.4 & 126 \\
\hline 4 & $55+59+106+92$ & 78 & 25 & 125 \\
\hline
\end{tabular}


These results show that the simulation model does not recognize the demand increasing in the period 2. So the backorder is inevitable and gets worse due to plant capacity limitation (95 units) insufficient to supply the simulated demand.

Table 2 - Simulation results

\begin{tabular}{|c|c|c|c|c|c|}
\hline \multicolumn{6}{|c|}{$\mathrm{L}=1, \mathrm{z}=1.88$ (service level of 97\%) } \\
\hline Period & $\mathrm{s}$ & $\begin{array}{c}\text { Production } \\
\text { before demand }\end{array}$ & $\begin{array}{c}\text { Inventory before } \\
\text { order processing }\end{array}$ & $\begin{array}{c}\text { Inventory after } \\
\text { order processing }\end{array}$ & $\begin{array}{c}\text { simulated } \\
\text { demand }\end{array}$ \\
\hline 1 & 55 & 55 & 55 & -4 & 59 \\
\hline 2 & 62 & 66 & 62 & -44 & 106 \\
\hline 3 & 126 & 95 & 51 & -41 & 92 \\
\hline 4 & 125 & 95 & 54 & -45 & 99 \\
\hline
\end{tabular}

\subsection{Integration of the methodologies}

The simulation model of the assembly plant gets its parameters from the output of the logistic model related to the assembly plant, Figure 4 . Then the production capacity is equal to 95 units and the initial production order equals to 55 (forecasted demand) +10 (demand anticipation determined by logistic model). The inventory policy is the same of the last subsection. The demand behavior follows a normal function with mean equals to the forecasted demand and $5 \%$ of standard. The average demand is based on the forecasted demand and simulated demand as shown in the table 3.

Table 3 - Value of $\mathrm{s}$

\begin{tabular}{|c|l|l|c|c|c|}
\hline $\begin{array}{l}\text { Beginning } \\
\text { Of Period }\end{array}$ & $\begin{array}{l}\text { Forecasted } \\
\text { Demand }\end{array}$ & $\begin{array}{l}\text { Simulated } \\
\text { Demand }\end{array}$ & Average & $\begin{array}{l}\text { Standard } \\
\text { Deviation }\end{array}$ & $\mathrm{s}$ \\
\hline 1 & 55 & & 55 & 0 & 55 \\
\hline 2 & 100 & 59 & 79.5 & 29 & 109 \\
\hline 3 & 100 & $59+106$ & 88.3 & 25.6 & 114 \\
\hline 4 & 95 & $59+106+92$ & 88 & 20,2 & 108 \\
\hline
\end{tabular}

The $s$ value of second period is based on the present simulated demand and on the forecasted demand of second period. The $s$ value of the third period is based on the first and second simulated demand and the forecasted demand of the third period and so on. The 4 periods simulation results:

Table 4 - Simulation results

\begin{tabular}{|c|c|c|c|c|c|}
\hline \multicolumn{7}{|c|}{$\mathrm{L}=1$} \\
\hline Period & $\begin{array}{c}\mathrm{s}+ \\
\text { anticipation }\end{array}$ & $\begin{array}{c}\text { Production } \\
\text { before demand }\end{array}$ & $\begin{array}{c}\text { Inventory before } \\
\text { order processing }\end{array}$ & $\begin{array}{c}\text { Inventory after } \\
\text { order processing }\end{array}$ & $\begin{array}{c}\text { simulated } \\
\text { demand }\end{array}$ \\
\hline 1 & $55+10$ & 65 & 65 & 6 & 59 \\
\hline 2 & $109+0$ & 95 & 101 & -5 & 106 \\
\hline 3 & 114 & 95 & 90 & -2 & 92 \\
\hline 4 & 108 & 95 & 93 & -6 & 99 \\
\hline
\end{tabular}


The Figure 4 shows a production anticipation of 10 units in the period 1, since the demand of period 2 cannot be entirely supplied by the production of the period 2 . The same fact occurs in the period 3. Then the temporal optimization recognizes future needs and anticipate the production. The simulation starts with 55 units in the first period, but the anticipation order is added to it, so the model produces 65 units in the first period. Every production anticipated by the optimization is considered along the simulation.

\section{CONCLUSION}

This paper presented a two-level environment to support planning decisions in an integrated supply chain. A case study showed the importance of the integration of two complementary approaches. The optimization was used as a logistic model while the simulation evaluated the operational behavior of the proposed logistic planning. The key issue in a supply chain is the synchronization of operation among supply chain enterprises by using an integrated planning methodology possible only by coupling analytical with evaluative technique.

\section{Acknowledgements}

This work was supported in part by CNPq, the Brazilian National Research Council, under grants $N^{\circ} 301359 / 96-2$ and $N^{\circ} 300891 / 90-3$ and FAPESP (The State of São Paulo Research Foundation).

\section{REFERENCES}

1. Azadivar, F. (1999) Simulation Optimization Methodologies. Proceedings of the 1999 Winter Simulation Conference. December 5-8, Squaw Peak, Phoenix, AZ.

2. Carvalho, M.F.; Fernandes, C. A and Ferreira, P.A (1999) Multiproduct Multistage Production Scheduling (Mmps) for Manufacturing Systems. Production Planning \& Control. Taylor \& Francis, London, vol. 10, n.7, 671-681.

3. Carvalho, M.F.; Furtado, P.G. (2002) Optimization Structures for Supply Chain Management. IFIP - Proceedings of Third Working Conference on Infrastructures for Virtual Enterprises (PROVE'03). May 1-3, Sesimbra, Portugal.

4. Carvalho, M.F.; Machado, C. (2002) Environment for Design and Analysis of System Integration. IFIP - Proceedings of Second Working Conference on Infrastructures for Virtual Enterprises (PRO-VE'02). December 4-6, Florianópolis, Brazil.

5. Gershwin, S.B. and Hildebrant, R.Suri (1986) A Control Perspectives on Systems. IEEE Control System Magazine, vol. 6, n.2, 3-15.

6. Law, A. (2002) Simulation-based Optimization. Proceedings of the 2002 Winter Simulation Conference. December 8-11, Manchester Grand Hyatt San Diego, San Diego, CA

7. Lee, H.L., V. Padmanabhan and S. Whang (1997) Information distortion in a supply chain: the bullwhip effect. Management Science, n. 43, 546-558.

8. Lee,S.M. and Paek,J.H. An enlarged JIT programme: its impact on JIT implementation and performance of the production System, Production Planning \& Control, 1995,vol. 6, n. 2, 185-191.

9. Simchi-Levi, D. and Kaminsky, P. and Simchi-Levi, E. (2000) Designing and managing the supply chain - concepts, strategies, and case studies, McGraw-Hill. 